Rabaska

Revue d'ethnologie de l'Amérique française

\title{
Hommage à Conrad Laforte (1921-2008)
}

\section{Jean-Pierre Pichette}

Volume 7, 2009

URI : https://id.erudit.org/iderudit/038348ar

DOI : https://doi.org/10.7202/038348ar

Aller au sommaire du numéro

Éditeur(s)

Société québécoise d'ethnologie

ISSN

1703-7433 (imprimé)

1916-7350 (numérique)

Découvrir la revue

Citer ce document

Pichette, J.-P. (2009). Hommage à Conrad Laforte (1921-2008). Rabaska, 7 ,

145-147. https://doi.org/10.7202/038348ar d'utilisation que vous pouvez consulter en ligne.

https://apropos.erudit.org/fr/usagers/politique-dutilisation/ 


\section{Hommage à Conrad Laforte (1921-2008)}

Après le père Anselme Chiasson, Roger Matton, Carmen Roy, Dominique Gauthier, et le père Germain Lemieux en avril dernier, voilà que disparaît le dernier témoin des Archives de folklore de l'Université Laval. Conrad Laforte est mort à l'Hôpital général de Québec le 4 septembre 2008, à l'âge de 86 ans. Ce court texte ne prétend pas rappeler le détail de son œuvre, qui compte une vingtaine de livres consacrés pour l'essentiel à son domaine de prédilection et dont le Catalogue de la chanson folklorique française reste sans contredit la pièce mâ̂tresse $^{1}$. Il s'agit plutôt de quelques réflexions que m'inspire sa carrière, que j'ai suivie depuis 1968 tantôt de près - comme étudiant, puis collaborateur à l'édition de ses recueils de contes populaires et autres écrits, enfin en tant que jeune

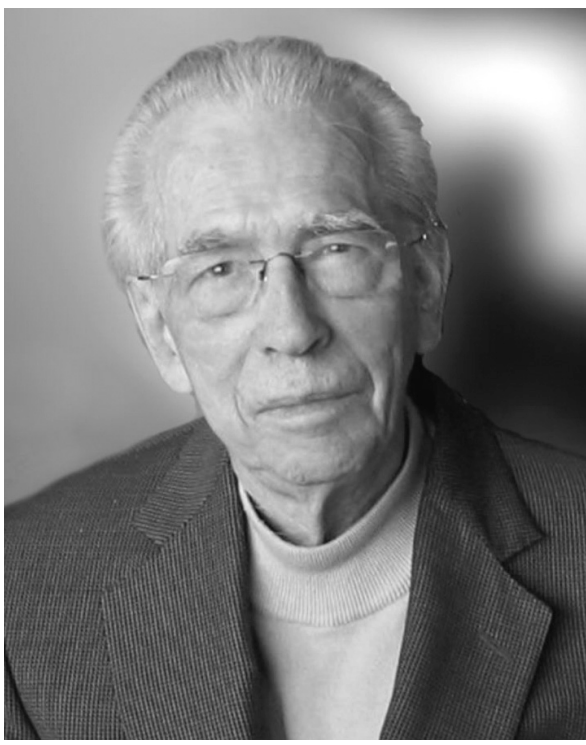

Conrad Laforte

Source : collection privée, 2001 collègue - , tantôt de loin.

$$
* * *
$$

\section{La détermination}

Embauché comme bibliothécaire-archiviste pour «mettre de l'ordre » dans les archives qui s'accumulaient, Conrad Laforte s'y employa d'abord et avant tout, cataloguant pour la bibliothèque générale tous les livres, même ceux de ses collègues parfois, et constituant tous les fichiers de consultation dont certains sont toujours actifs aux Archives de l'Université Laval. Parallèlement

1. Voir le « portrait» de Conrad Laforte dans le premier Rabaska (2003), p. [79]-112, où on trouvera une notice biographique, de larges extraits de l'entrevue «L'air ne fait pas la chanson » qu'il m'avait accordée les 30 et 31 juillet 2002, et sa bibliographie. 
à son travail, il se fit aussi étudiant et obtint tous les diplômes de la licence au doctorat, sans aucun passe-droit ; il fut dès lors le premier et le seul docteur de la première équipe des Archives de folklore. Et c'est ainsi qu'il gravit progressivement tous les échelons de la carrière universitaire, du plus modeste, chargé de cours, au plus élevé, professeur titulaire. Sa détermination illustre combien il est vrai que des derniers deviennent les premiers...

\section{Les belles heures du terrain}

Avec ses maîtres, les Marius Barbeau, Félix-Antoine Savard et Luc Lacourcière, « qui [lui] ont tracé la voie » comme il le reconnaîtra sans peine dans une dédicace (1997), il s'était mis à l'écoute du peuple dont il avait noté les traditions directement sur le terrain. En se remémorant sa première cueillette de conte auprès d'un vieil informateur du rang de la Misère à BaieSaint-Paul, il était visiblement heureux :

C'était [le conte de] « Jean de Bois ». J'ai tout enregistré. C'est un conte assez extraordinaire, rabelaisien [...] un conte très long. J'étais avec $\mathrm{M}^{\mathrm{gr}}$ Savard puis Luc Lacourcière. Puis $\mathrm{M}^{\mathrm{gr}} \mathrm{Savard}$ riait fort, puis le conteur aussi il riait tout le temps, puis moi je riais aussi. Moi, je riais moins fort parce que je m'occupais de l'enregistrer : c'était mon informateur puis c'est moi qui faisais l'enquête. Ah c'était agréable. Les relations avec Lacourcière puis Savard, l'équipe du début là, c'était convivial.

Ce moment primordial, partagé dans l'amitié et la complicité des premières heures, alors qu'il découvrait ces « menteries drôles et merveilleuses » chez des gens humbles, simples comme lui, il le racontait en s'émerveillant encore devant la richesse inouïe de sa récolte et la générosité de ses informateurs. Il aurait pu faire sienne cette parole : «Ce que tu as caché aux sages et aux intelligents, tu l'as révélé aux humbles et aux petits ».

\section{Le grand œuvre}

Amateur d'ordre, travailleur méthodique, qui avait la patience nécessaire pour la recherche, Conrad Laforte était donc un homme volontaire qui savait ce qu'il voulait et qui a mené à terme l'essentiel de ce qu'il a entrepris. S'il possédait l'humilité et la candeur du chercheur, il avait très nettement conscience de la valeur de ses travaux. Ce qui est aussi de l'humilité. Lui qui, sans idée préconçue, s'était laissé guider par ses professeurs, par le terrain, par ses lectures, par ses documents, ne se laissa jamais séduire par l'enrobage de la nouveauté, par le cortège des vedettes à panache ou par le discours flamboyant des beaux parleurs remorquant la dernière théorie à la mode. Toute son œuvre, large passerelle lancée entre l'Amérique française et la 
francophonie européenne, il l'a portée avec persévérance à la suite de ses maîtres, et parfois contre eux, avec l'assurance paisible aussi de celui qui a remonté le fleuve jusqu'à la source.

\section{La reconnaissance}

En 1988, au terme du Congrès international sur les ballades et les chansons folkloriques que Conrad Laforte avait attiré et organisé à l'Université Laval, Stefaan Top, le président de la Commission de la Société internationale d'ethnologie et de folklore (SIEF), lui rendait ce témoignage :

[...] si l'Université Laval est à la tête dans le domaine de la chanson folklorique, c'est grâce entre autres à notre cher collègue Conrad Laforte, qui, presque annuellement, comme une sorte de couronnement de sa carrière, publie un livre important sur la chanson francophone. [...] N'oublions jamais que la Mecque des études sur la chanson francophone n'est ni Paris, ni Bruxelles, ni Genève, mais l'Université Laval à Québec.

Il me plaît de penser que la pierre posée par Conrad Laforte compte pour l'une des assises principales de la discipline en ce pays et que son exemple permettra à ceux qui désespèrent parfois de secouer la léthargie ou la morosité qui les menace à l'occasion, car il nous a montré, s'il en était besoin, que Rome ne s'est pas faite en un jour.

Le jour de son $79^{\mathrm{e}}$ anniversaire, le vendredi 10 novembre 2000, à l'église Sainte-Anne-des-Pins de Sudbury, j'avais le plaisir de présenter Conrad Laforte au rang de Docteur en lettres sacrées honoris causa de l'Université de Sudbury. Le département de Folklore et ethnologie de l'Amérique française, pour bien marquer ses 25 ans d'existence, avait choisi d'honorer un ethnologue de grand renom, qui, par sa formation et ses activités intellectuelles, possédait des liens bien nets avec notre institution. C'était notre façon de lui dire que nous partagions tout à fait l'avis de Benoît Lacroix : « Conrad Laforte, me disait-il, c'est vraiment une carrière réussie! »

$$
* * *
$$

Avec le recul, je pense que le titre que nous avions ensemble donné à son portrait - «L'air ne fait pas la chanson »- lui était tout à fait approprié : au sens propre bien sûr, parce qu'il évoquait le point de vue particulier de Conrad Laforte et ses travaux sur les poétiques ou les textes de la chanson folklorique, tout comme au figuré, qui révélait la face cachée de sa carrière et ses grandes motivations. 